\title{
Androgen insensitivity with mental retardation: a contiguous gene syndrome?
}

H R Davies, I A Hughes, M O Savage, C A Quigley, M Trifiro, L Pinsky, T R Brown, M N Patterson

Department of

Paediatrics, University

of Cambridge,

Addenbrooke's

Hospital, Hills Road, Cambridge CB1 2QQ, UK

H R Davies

I A Hughes

M N Patterson

Department of

Endocrinology, St

Bartholomew's

Hospital, West

Smithfield, London,

EC1A 7BE, UK

M O Savage

Paediatric

Endocrinology, Riley

Hospital for Children,

Indiana University, 702

Barnhill Drive, Room

5984, Indianapolis,

Indiana 46202, USA

C A Quigley

Lady Davis Institute for Medical Research, McGill University,

Montreal, Quebec H3T 1E2, Canada

M Trifiro

L Pinsky

Department of

Population Dynamics, Division of

Reproductive Biology,

Johns Hopkins

University School of

Hygiene and Public

Health, 615 North

Wolfe Street,

Baltimore, MD 21205,

USA

T R Brown

Correspondence to: Professor Hughes.

Received 19 July 1996

Revised version accepted for publication

13 September 1996

\begin{abstract}
We present data to suggest the existence of a mental retardation (MR) locus at Xq11.2-q12 between DXS1 and DXS905, identified in two subjects with complete androgen insensitivity syndrome (CAIS) and MR. Androgen insensitivity syndrome is a disorder of male sexual differentiation caused by a defect in the androgen receptor (AR) gene (Xq11-q12). Two subjects with CAIS resulting from a complete deletion of the AR gene have previously been reported, one of whom also has $M R$. We have identified another mentally retarded person with a complete deletion of the AR gene. The deletion in the two patients with CAIS and MR extends past the AR gene and includes several marker loci both proximal and distal to the $A R$ gene, the limits of the deletions being DXS1 and DXS905. The deletions in the CAIS patients who do not have MR do not include any of the markers outside the $A R$ gene itself. These data suggest that located close to the AR gene is a gene which is implicated in non-specific $M R$. (F Med Genet 1997;34:158-160)
\end{abstract}

Keywords: X linked non-specific mental retardation; androgen insensitivity syndrome; androgen receptor.

There are believed to be at least eight distinct loci for non-specific mental retardation (MR) on the $\mathrm{X}$ chromosome. ${ }^{12}$ As there are no other physical characteristics associated with this type of MR it is not possible to combine the results of linkage analysis in different affected families. For this reason it has been difficult to map the genes involved. We present data to suggest the existence of a MR locus close to the gene for the androgen receptor (AR) on Xq11.2-12, between DXS1 and DXS905. The data derive from an analysis of four patients with complete androgen insensitivity syndrome (CAIS), two of whom also have MR.

Androgen insensitivity syndrome (AIS) is a disorder of male sexual differentiation caused by an inability to respond appropriately to the male sex hormones, androgens. ${ }^{3}$ Affected subjects have a 46,XY karyotype, testes, and either normal female external genitalia (complete
AIS) or a range of degrees of undervirilisation (partial AIS). The disorder is caused by a defect in the AR gene which lies on Xq11-12. Over 150 different mutations in the AR gene responsible for AIS have been reported to date, ${ }^{45}$ the vast majority being point mutations resulting in missense mutations. There have been four previous reports of large deletions of the AR gene, all of which result in the CAIS. We have had the opportunity to study three of these four patients. In two cases the entire coding region of the gene is deleted. ${ }^{67}$ One of these patients $(A R \Delta 1)$ is intellectually normal ${ }^{7}$; however, the other $(\mathrm{AR} \triangle 2)$ also has $M \mathrm{MR}^{6} \mathrm{~A}$ third patient (AR $\triangle \mathrm{D}-\mathrm{H})$ has a deletion of the five $3^{\prime}$ exons of the gene, exons $\mathrm{D}$ to $\mathrm{H}$, which code for the entire hormone binding domain of the receptor; this patient is intellectually normal. ${ }^{8}$ All of these deletions are submicroscopic. Limited deletion analysis was performed by Southern blotting in the original studies of both complete deletion patients, using cDNA probes to $\mathrm{X}$ chromosome loci in the region of the AR gene. The closest markers to the AR gene tested were DXS1 and PGK1P1 in AR $\triangle 1$ and DXS1 and DXS159 in AR 42 . In both cases all the markers outside the AR gene were present.

We have identified a third patient (AR $\Delta 3$ ) with CAIS resulting from a complete deletion of the coding region of the AR gene. The AR gene was examined by genomic PCR using conditions specific for the eight exons of the gene. ${ }^{9}$ Although PCR of control DNA produced the expected products, all exons of the AR gene failed to amplify from the patient's DNA. This patient also has MR and mild developmental abnormalities. She attends a special school, has impaired vision and developmental delay, mild hypertelorism, large hands and feet, high arched palate, a small chin, and downward slanting eyes. This phenotype is similar to AR $\Delta 2$ although slightly less severe.

A deletion analysis of all four of the above patients has shown that the $\mathrm{X}$ chromosome deletion in the two patients with MR extends past the AR gene in both directions, whereas in the patients with no MR the deletion is limited to the AR gene itself. The markers tested were: DXS1161, ${ }^{10}$ PGK1P1, ${ }^{11}$ DXS1160, ${ }^{10}$ 
A
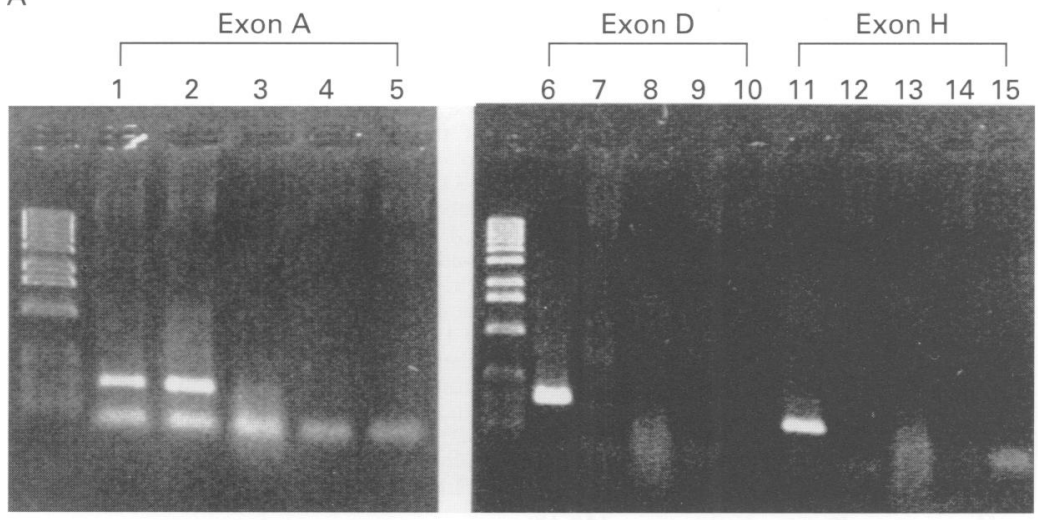

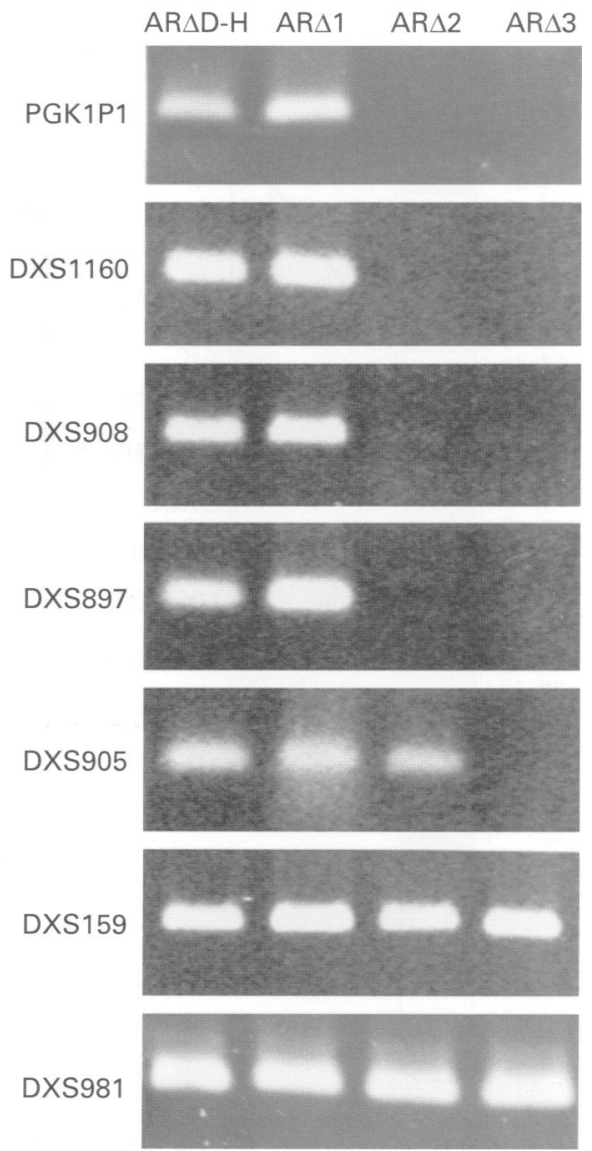

C

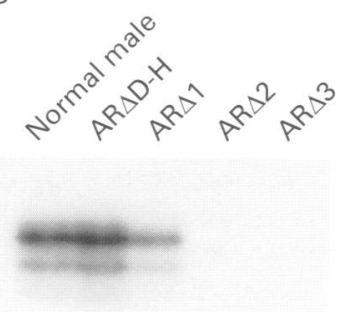

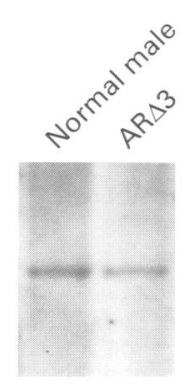

Figure 1 (A) Examples of AR gene PCRs: lanes 1, 6, and $11=$ normal male control, lanes 2, 7, and $12=A R \Delta D-H$, lanes 3,8 , and $13=A R \Delta 1$, lanes 4,9 , and $14=A R \Delta 2$, lanes 5,10 , and $15=A R \Delta 3$. (B) Southern blot analysis of DXS1 using probe p8 on genomic DNA from ARA3 and a normal male control, digested with EcoRI. (C) ${ }^{32} P$ labelled PCR products for DXS1161. This marker includes a CA repeat and therefore a ladder pattern is produced by Taq polymerase stuttering. (D) Results of deletion analysis of the four CAIS patients using PCR based markers distal to the AR gene.

DXS908, ${ }^{12}$ DXS897, ${ }^{12}$ DXS905, ${ }^{12}$ DXS159, ${ }^{13}$ and DXS981. ${ }^{14}$ All markers except for DXS1 161 were analysed by genomic PCR and the products visualised by agarose gel electrophoresis. The sense primer used for DXS1161 has sequence similarity to $\mathrm{L} 1$ repeats and, as recommended in the original publication, the antisense oligo was end labelled with ${ }^{32} \mathrm{P}$ and the products analysed on a standard polyacrylamide sequencing gel. ${ }^{10}$

Fig 1A shows examples of the PCR reactions for the $A R$ gene showing that $\operatorname{AR} \Delta 1, \operatorname{AR} \Delta 2$, and $A R \triangle 3$ are all deleted for the entire $A R$ gene, while AR $\triangle \mathrm{D}-\mathrm{H}$ is only deleted for the $3^{\prime}$ portion of the gene. Southern blot analysis of genomic DNA from patient AR $\Delta 3$ using probe p8 (obtained from ATCC) for DXS1 confirmed that, as in the other patients, this marker is present (fig 1B). The deletion in AR $\Delta 3$ is slightly greater than that in AR $\triangle 2$, extending from DXS1161 to DXS905. In AR $\triangle 2$ the deletion extends from DXS1 161 but only as far as DXS897. The results of the PCR analysis are shown in figs $1 C$ and $D$ and in schematic form in fig 2 .

These results suggest that there is a locus for MR between DXS1 and DXS905, which is deleted in the two patients with CAIS and MR but not in the patients without MR. Several reports of linkage analysis in families with nonspecific X linked MR have mapped a locus for
MR to this region. ${ }^{1}$ This study provides a more precise estimate for the position of a locus for $\mathrm{X}$ linked MR near to the AR gene. Until candidate genes are characterised it is not possible to say whether the locus we have identified corresponds to any loci for non-specific $\mathrm{X}$ linked MR mapped by linkage analysis.

A possible candidate gene which has been mapped to this region is EPLG2, a potential ligand for ELK, a member of the EPH family of receptor tyrosine kinases. ELK is expressed exclusively in brain and testis and has been suggested to play a role in the development or maintenance of the nervous system. ${ }^{17}$ The gene for EPLG2 itself has been mapped to a $200 \mathrm{~kb}$ interval on Xq12, distal to PGK1P1 and on the same YAC as PGK1P1, DXS159, and DXS133. ${ }^{19}$ Although EPLG2 has not been detected in adult human brain by northern blot analysis, it does appear to be expressed in developing rat brain. ${ }^{18}$ Further characterisation of this ligand, together with the identification of other genes in this region of the $\mathrm{X}$ chromosome, will help to determine the gene (or genes) responsible for $M R$ in these patients.

This work was supported by the Wellcome Trust.

1 Lubs HA, Chiurazzi P, Arena JF, Schwartz C, Tranebjaer L, Neri G. XIMR genes: update 1996. Am F Med Genet 1996;64:147-57. 


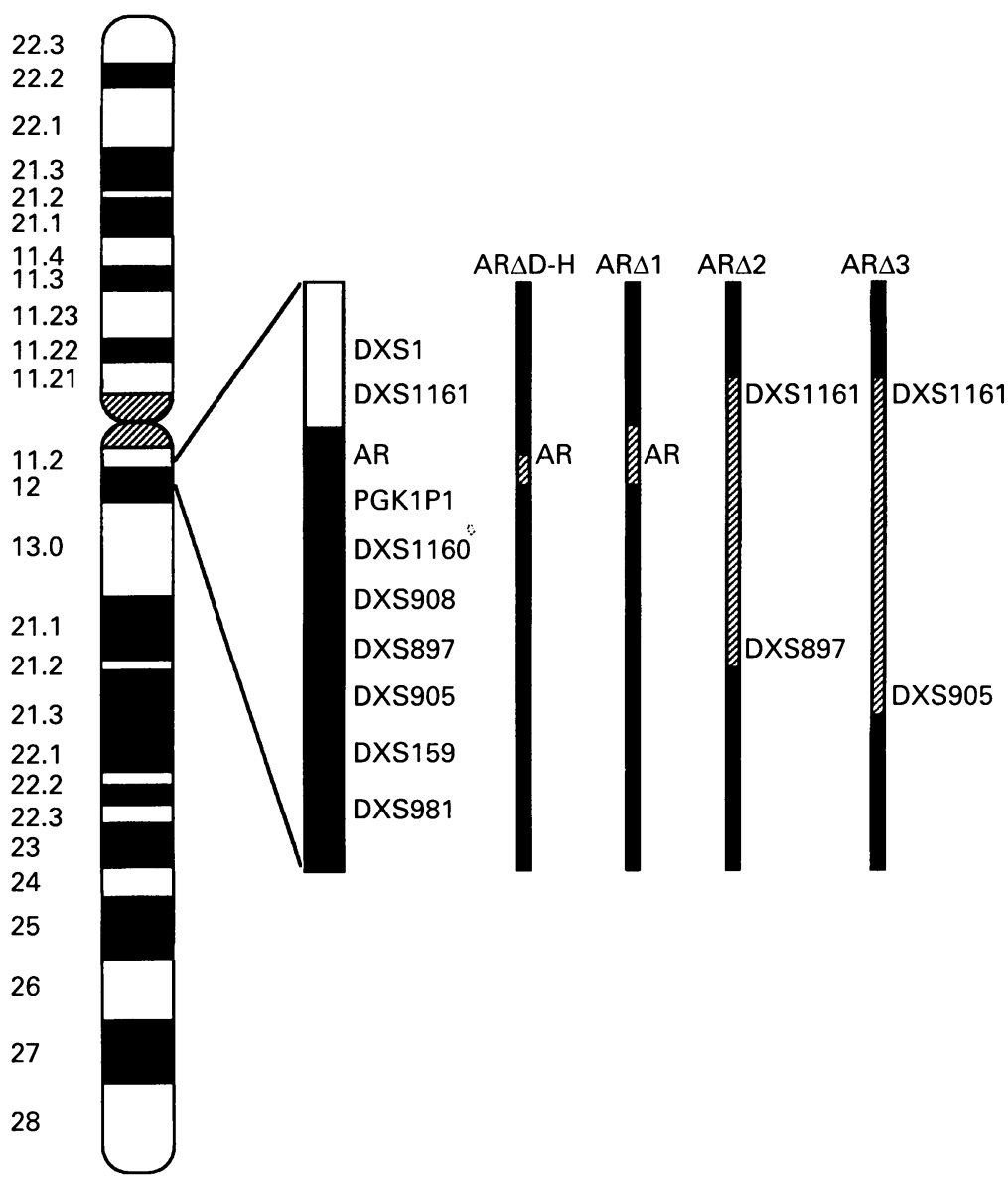

Figure 2 A schematic representation of the extent of the $X$ chromosome deletions in each of the four patients studied. The hatched areas represent the regions deleted in each case. Only the AR gene markers are deleted in $A R \triangle D-H$ and $A R A 1$. The deletion in $A R \triangle 2$ extends from DXS1161 to DXS897, while the deletion in ARA3 is slightly larger, extending from DXS1161 to DXS905. The order of the markers is taken from the report of the Sixth International Workshop on Human X-Chromosome Mapping. ${ }^{15}$ The estimated size of the deletion between DXS1 and DXS905 is 1.5 megabases. ${ }^{15}$ Note that the orientation of the partial AR gene deletion in $A R \Delta D-H$ has been illustrated to take account of recent evidence that the AR gene is transcribed away from the centromere. ${ }^{16}$

2 Gedeon AK, Donnelly AJ, Mulley JC, Kerr B, Turner G. How many X-linked genes for non-specific mental retarda-
tion (MRX) are there? Am $\mathcal{F}$ Med Genet 1996;64:158-62.

3 Quigley C, De Bellis A, Marschke K, El-Awady M, Wilson Quigley C, De Bellis A, Marschke K, El-Awady M, Wilson E, French F. Androgen receptor defects: historical, clinical and 321 .

4 Patterson M, Hughes I, Gottlieb B, Pinsky L. The androgen receptor gene mutations database. Nucleic Acids Res 1994;22:3560-2

5 Gottlieb B, Trifiro M, Lumbroso R, Vasiliou DM, Pinsky L. The androgen receptor gene mutations database. Nucleic Acids Res 1996;24:151-4
6 Trifiro M, Gottlieb B, Pinsky $\mathrm{L}$, et al. The $56 / 58 \mathrm{kDa}$ androgen-binding protein in male genital skin fibroblast with a deleted androgen receptor gene. Mol Cell Endocrino 1991;75:37-47

7 Quigley C, Friedman KJ, Johnson A, et al. Complete deletion of the androgen receptor: definition of the null phenotype of the androgen insensitivity syndrome and determination of carrier status. $f$ Clin Endocrinol Metab 1992;74:927-33.

8 Brown TR, Lubahn DB, Wilson EM, Joseph DR, French FS, Migeon CJ. Deletion of the steroid binding domain of the human androgen receptor gene in one family with complete androgen insensitivity syndrome: evidence for further genetic heterogeneity in this syndrome. Proc Natl Acad Sci USA 1988;85:8151-5.

9 Batch JA, Williams DM, Davies HR, et al. Androgen receptor gene mutations identified by SSCP in fourteen subjects wh androgen insensitivity syndrome. Hum Mol Gene with androgen inser

10 Barker DF, Fain PR. Definition and mapping of STSs at STR and RFLP loci in Xp11-Xq22. Genomics 1993;18: 712-16.

11 Browne DL, Zonana J, Litt M. Dinucleotide repeat polymorphism at the PGK1P1 locus. Nucleic Acids Res 1992;20:1169.

12 Cole CG, Goodfellow PN, Bobrow M, Bentely DR Generation of novel sequence tagged sites (STSs) from discrete chromosomal regions using Alu-PCR. Genomics discrete chromoso

13 Kere J, Grzeschik KH, Gremaud M, Schlessinger D, De La Chapelle A. Anhidrotic ectodermal dysplasia gene region cloned in yeast artificial chromosomes. Genomics 1993;16: 305-10.

14 Mahtani M, Willard HF. A polymorphic X-linked tetranucleotide repeat locus displaying a high rate of new mutation: mutation: implications for mechanisms of mutation at

15 Nelson DL, Ballabio A, Cremers F, Monaco AP, Schlessinger $\mathrm{D}$. Report of the sixth international workshop on human X chromosome mapping 1995. Cytogenet Cell Genet 1995;71:307-42.

16 Miller AP, Graves MK, Monaco AP, Eble B, Schlessinger D, Willard $\mathrm{HF}$. Progress in mapping the pericentromeric region of the human $\mathrm{X}$ chromosome: YAC contigs spanning Xp11.21-p11.22 and Xq11.2-q12 (Abstract N5) The X Chromosome Virtual Workshop 1995;URL:http:// gc.bcm.tmc.edu:8088/chrx/home.html

17 Lhotak V, Greer P, Letwin K, Pawson T. Characterization of Elk, a brain-specific receptor tyrosine kinase. Mol Cell Biol 1991;11:2496-502.

18 Fletcher FA, Carpenter MK, Shilling $\mathrm{H}$, et al. LERK-2, a binding protein for receptor-tyrosine kinase ELK, is evolutionarily conserved and expressed in a developmentally regulated pattern. Oncogene 1994;9:3241-7.

19 Fletcher FA, Huebner K, Shaffer LG, et al Assignment of the gene (EPLG2) encoding a high-affinity binding protein for the receptor tyrosine kinase Elk to a 200-kilobasepair region in human chromosome Xq12. Genomics 1995;25: $334-5$.

\section{Note added in proof}

As this paper was in press, another complete deletion of the AR gene was reported by Hiort et $a F^{\prime \prime}$ in a CAIS patient. The extent of the deletion is not indicated nor whether the patient is mentally retarded.

20 Hiort O, Sinnecker GHG, Holterhus PM, Nitsche EM, Kruse $\mathrm{K}$. The clinical and molecular spectrum of androgen insensitivity syndromes. Am F Med Genet 1996;63:218-22. 